\title{
A data-driven modeling method for an aero gas turbine engine system based on the transient data
}

Sangjo Kim ( $\square$ sangjoemail@gmail.com )

Agency for Defense Development

Research Article

Keywords:

Posted Date: January 20th, 2022

DOI: https://doi.org/10.21203/rs.3.rs-1265089/v1

License: (c) (i) This work is licensed under a Creative Commons Attribution 4.0 International License. Read Full License 


\section{Abstract}

Accurate performance prediction models in gas turbines are essential for diagnosis. In this paper, a datadriven modeling method is newly proposed for an aero gas turbine engine system with high prediction accuracy during dynamic operation by considering the time delay included in the measured temperature from a sensor. Modeling and analysis are performed using an aero gas turbine engine with rapid thrust change. The accuracy of the data-driven model trained using the measured temperature and the flow temperature calculated through physical relations is compared. The flow temperature is calculated from the measured temperature based on lumped system analysis. In data learning, the low-pressure shaft speed and low-pressure turbine total temperature are defined as input parameters, whilst engine net thrust, and fuel mass flow rate are defined as output ones. The results show that using the measured temperature for training without conversion adversely affects the accuracy of the data-driven model. The flow temperature converted from the measured values is reasonable in terms of thermodynamic cycle matching of the engine. It is confirmed that the accuracy of the data-driven model is significantly improved when the actual flow temperature is used for model training.

\section{Introduction}

The necessity of diagnosis and prognosis of gas turbines is gradually increased $[1,2,3]$ to operate it efficiently and to prevent serious damage in advance. With industrial gas turbines, diagnosis can be used to predict the degree of compressor fouling and [4] to reduce operating costs through optimal compressor washing [5]. The cost of inspection of the gas turbines can be reduced by screening out malfunctioning components through diagnosis [6] and prognosis can predict the remaining life of components, which can reduce component replacement costs [7]. The operation safety and accuracy of a gas turbine control could be improved by sensor fault diagnosis [8]. In general, the impact on life is calculated based on operating time and the operating conditions of gas turbines, whilst maintenance and parts replacement are performed based on the remaining life [9]. Recently, due to the development of data processing methods, data-driven model techniques and physical model techniques, many studies of diagnosis and prognosis in gas turbines have been made.

In general gas turbine diagnosis, this is judged as malfunctional when abnormal data is found through analysis of the difference between the measured data and normal data. For civilian aircraft with little change in mission profile, the anomaly is determined by comparing the measured data under cruise conditions with the normal data. In the case of military aircraft with a significant change in mission profile, the history of the measured value over time in take-off operation is compared with the normal data to determine whether there is an abnormality. Normal data in a gas turbine can be predicted based on a lot of data accumulated in the past or through a physics-based model.

In a physics-based model, gas turbine performance is calculated using performance maps representing the characteristics of a component, and conservation equations for mass, energy, and momentum [10, 11]. Many studies have been conducted to determine an effective method for calibrating a physics-based 
model using real measurement data so as to improve the prediction accuracy $[12,13,14]$. In gas turbine performance adaptation, there is a method for calibrating a performance map of compressors and turbines based on engine measurement data. To calibrate the performance map, studies have been conducted to adjust the flow rate, pressure ratio, and efficiency at a specific rotation speed through scaling factors $[15,16]$. Tsoutsanis et al. [17] conducted calibrating a compressor performance map by adjusting the shape of the map curve. Kim et al. [18] proposed a method to correct the local measured value by applying correlation for the difference between the predicted value from an engine model and the actual measured value as a function of the corrected rotating speed.

There have been many studies on the method of predicting gas turbine performance using data-driven models. Basso et al. [19] conducted one applying a nonlinear autoregressive neural network with the exogenous inputs (NARX) model in an industrial gas turbine. Nikpey et al. [20] conducted data-driven modeling by applying an artificial neural network (ANN) model in a combined heat and power micro gas turbine. Rahnama et al. [21] introduced ANN identification techniques to estimate combined cycle, singleshaft heavy duty, gas turbine dynamic behaviors. Lu and Gao [22] obtained a reduced-order model using a data-driven model in a three-shaft aircraft gas turbine engine. A fault detection filter was designed to detect actuator and sensor faults using the reduced-order model. Asgari et al. [23] conducted a study to create a NARX model in single-shaft industrial gas turbines. The NARX model was created using the measured values in the start-up operation, and it was confirmed that the system dynamics were well predicted. Yu and Shu [24] studied a NARX model for predicting the performance after the idle condition in an aircraft turbofan engine. They built the NARX model using the data calculated using the physicsbased model and verified it through dynamic simulation. Bahlawan et al. [25] applied a NARX method to create a model for predicting start-up performance according to ambient temperature conditions in a single-shaft industrial gas turbine. Salehi and Montazeri [26] presented a black box modeling approach based on a NARX structure to model accurately the fuel control unit in a turboshaft engine. De Giorgi et al. [27] conducted data-driven modeling using an ANN to predict turbine exhaust gas temperature during dynamic operation. Liu and Karimi [28] introduced a data-driven method using surrogate models to predict gas turbine part-load and full-load performance.

Gas turbines are often operated under dynamic conditions, such as fast start-up in industrial gas turbines and take-off in aircraft engines. Dynamic and steady-state operation have different physical characteristics. Kim et al. [29] proposed a method to increase the prediction accuracy by considering the additional power consumption of rotors due to acceleration and deceleration when constructing a datadriven model using gas turbine dynamic operation data. This means that when constructing a data-driven model using measured values in dynamic operation, it is possible to create an accurate performance model by sufficiently considering the physical characteristics.

The measured values under dynamic operating conditions differ from actual fluid properties due to the response time of sensors, unlike the measurement under steady-state conditions [30, 31]. Specifically in the case of temperature sensors located in the turbine exhaust, additional structures were employed to prevent direct contact of hot combustion gases so as to increase sensor life [32]. A time delay in the 
measured temperature occurs because of heat conduction in the structures. Kim et al. [33] separated actual fluid temperature from measured temperature at the gas turbine outlet through lumped system analysis under dynamic operating conditions. They performed physics-based model adaptation using the separated fluid temperature to increase prediction accuracy. For the studies relating to data-driven models in a gas turbine described above, measured temperature without conversion for model training was utilized. However, the time delay error due to the dynamic operation included in the temperature measurement can affect the prediction accuracy of a data-driven model. For this reason, the effect of the time delay error included in the temperature sensors on the accuracy of a data-driven model needs to be ascertained. Moreover, a method for minimizing the effect of the time delay error in the model is also required to improve the prediction accuracy.

For the current study, a data-driven modeling method considering the time delay included in the measured temperature from a sensor is introduced for predicting engine performance during dynamic operation. The data-driven model for estimating thrust and fuel consumption was generated using the rotating speed and turbine temperature as input parameters. The measured temperature and actual fluid temperature were separated based on the lumped system analysis method. In addition, a data-driven model was generated using the separated fluid temperature to improve the accuracy of the model. A gas turbine engine for an aircraft was used to analyze and verify the proposed method.

\section{Procedure For Data-driven Model Generation}

Conventionally, a data-driven model for gas turbine engines is generated through a machine learning process based on real measurement data. However, there are differences in the values and characteristics between the measurement data and real flow properties for various reasons, such as when the fluid property in the measurement plane has a distribution and the measured value from a sensor is different from the averaged value or when the measurement time step differs from the actual behavior. In particular, in the case of a temperature sensor, there is a difference between the measured value and actual temperature due to a time delay error, which depends on the measuring point as well as the type and shape of the sensor. However, in general, the time delay error is large for temperature sensors located in the high temperature region of a gas turbine. Hence, for this study an additional step for measurement data treatment aimed at excluding the time delay error in the measured temperature for data-driven model generation is proposed. Figure 1 presents the schematic flow chart for data-driven model generation with both the conventional and proposed approaches.

\section{Test Engine}

The gas turbine considered in this study is a military turbofan engine with rapid thrust changes. Specifically, the F100 turbofan engine applied to an F-15 airplane was used. This turbofan engine consists of a 3-stage fan, 10-stage high-pressure compressor (HPC), combustor, 2-stage high-pressure turbine, 2-stage low-pressure turbine (LPT), afterburner, bypass duct, and nozzle, as shown in Figure 2. The flow at the LPT outlet was split into the HPC and bypass duct, and the two flows were mixed at the 
outlet of the LPT. For data-driven model training, measurement data from a throttle frequency sweep maneuver, as shown in Ray's study [34], were used. Figure 3 presents the LPT inlet total temperature, LP shaft speed, engine net thrust, and fuel mass flow rate during a throttle frequency sweep maneuver.

\section{Measured Temperature Treatment}

The purpose of this study was to compare the use of measured temperature from a sensor in data-driven modeling without conversion, and the use of temperature excluding the time delay error included in dynamic maneuvering. The procedure for the measured temperature treatment is presented in Figure 4. As suggested by Kim et al. [33], in the case of a temperature sensor located in a high temperature region, several thick structures are used to increase its life. A time delay error occurs for the measured temperature due to conduction of the structures. Kim et al. [33] excluded the time delay error from the measured temperature by the lumped system analysis. The temperature sensor can be defined as a solid body in a lumped system. Eq. 1 presents the energy conservation equation in the lumped system. In Eq. 1, the term on the left-hand side is the amount of energy transferred from the main flow to the sensor. The term on the right-hand side is the amount of energy change in the sensor. Eq. 3 can be obtained by rearranging and integrating both sides of Eq. 1 and Eq. 2. Finally, Eq. 4 can be summarized from Eq. 3, with the variable $b$ referring to a time constant, as expressed in Eq. 5 . In this study, sensor temperature and flow temperature were separated using Eq. 4. In a lumped system, the temperature change over time is determined by a time constant b. In step 2, an initial time constant value is defined and then the flow temperature is calculated using the lumped system analysis with the initial time constant value in step 3. In the lumped system, the flow temperature is affected by the gradient of the measured temperature in addition to the time constant value. However, there will be abnormal gradient values during the lumped system analysis, because of the unavoidable noise in the measured data. Therefore, to minimize this effect, the calculated flow temperature has been corrected based on the trend of the fuel flow in step 4 . The reaction of the fuel and air in the combustor takes place in a very short time period, and the flow velocity in a turbine is also very fast. For this reason, the fuel flow rate to a combustor and temperature response at the turbine outlet should be almost the same. In this study, the time constant b was determined to make the response of the temperature at the turbine outlet and the fuel mass flow rate similar. In step 5, whether the difference between the gradient of the flow temperature change and the target gradient value becomes $10^{-4}$ at the selected time is checked. The target gradient value is 0 , which equals the gradient of the fuel change at the selected time. If the criteria are not satisfied in step 5 , the time constant value is changed in step 6 , and steps 3 to 5 are repeated. Through this process, the final flow temperature can be obtained in step 7 .

$$
h A_{\text {Sensor }}\left(T_{\text {Flow }}-T_{\text {Sensor }}\right) d t=m_{\text {Sensor }} C p_{\text {Sensor }} d T
$$




$$
\frac{d\left(T_{\text {Sensor }}-T_{\text {Flow }}\right)}{T_{\text {Sensor }}-T_{\text {Flow }}}=-\frac{h A_{\text {Sensor }}}{m_{\text {Sensor }} C_{\text {pSensor }}} d t
$$

$$
\ln \frac{T_{\text {Sensor }}(t)-T_{\text {Flow }}}{T_{\text {Sensor }}-T_{\text {Flow }}}=-\frac{h A_{\text {Sensor }}}{m_{\text {Sensor }} C_{\text {pSensor }}} t
$$

$$
\frac{T_{\text {Sensor }}(t)-T_{\text {Flow }}}{T_{\text {Sensor }}-T_{\text {Flow }}}=e^{-b t}
$$

4

$$
b=\frac{h A_{\text {Sensor }}}{m_{\text {Sensor }} C_{\text {pSensor }}}
$$

Figure 5 presents the fuel mass flow rate, measured temperature from the sensor, and separated flow temperature with time. In the figure, the fuel mass flow rate has local maximum values around 16, 25 and 31 seconds. The measured temperature from the sensor has a local maximum at a later time than the fuel mass flow rate. However, the flow temperature calculated by the lumped system analysis method with time constant $b$ has a local maximum at a point similar to the fuel mass flow rate. At around 11, 22, 28 , and 33 seconds, the local minimum fuel mass flow rate has a similar value, whereas the measured temperature from the sensor has a different value at the same time point. Over time, the local minimum temperature at the sensor gradually increases. Regarding the measured engine net thrust, as presented in Figure 3 , this has a similar value at the local minimum fuel mass flow point. The fact that the turbine temperature has a different value at the same fuel flow rate and engine net thrust means that the measured value is not appropriate in terms of thermodynamic cycle matching. For this study, data-driven modeling was performed using the measured temperature from a sensor and separated flow temperature, with the results being compared.

\section{Data-driven Modeling}

A data-driven model was generated using a feed-forward network with sigmoid hidden neurons and linear output neurons, as shown in Figure 6. The Levenberg-Marquardt backpropagation algorithm was used for data learning. The number of hidden neurons was defined as 10. The goal of this research was to generate a data-driven model for predicting engine net thrust and fuel consumption. The input parameters in the data-driven model were defined as the LP shaft speed and LPT inlet total temperature. In general, the thrust at a gas turbine nozzle is calculated using the gas mass flow rate and flow velocity 
at the nozzle outlet. The flow velocity at the nozzle outlet is calculated based on the gas mass flow rate, cross sectional area, and flow density. The gas mass flow rate in an aero gas turbine is determined by the operating characteristics of a fan. Hence, the LP shaft speed that can represent the operating characteristics of a fan was selected as an input parameter for learning the data-driven model. In addition, since the state of the fluid in a nozzle is directly related to the temperature in turbines, the LPT inlet total temperature was selected as the input parameter for training this model. Table 1 shows the parameters and ranges for training and validation of the data-driven model. For the data learning, measurement data from 0 to 25 seconds were used, whilst for the data-driven model validation, the measured data for 25 to 35 seconds was used. The range of measurement data used for model learning included the range of the measurement data for validation. The model generated using the measured LPT inlet total temperature by the sensor has been termed an original data-driven model, whilst that using the separated fluid temperature from the measured data has been called a revised data-driven model.

Table 1

Input and output parameters for the data-driven model

\begin{tabular}{|c|c|c|c|c|c|}
\hline \multirow[t]{2}{*}{ Type } & \multicolumn{3}{|c|}{ Data-driven model input } & \multicolumn{2}{|c|}{ Data-driven model output } \\
\hline & $\begin{array}{l}\text { LPT inlet total } \\
\text { temperature (sensor) }\end{array}$ & $\begin{array}{l}\text { LPT inlet total } \\
\text { temperature (flow) }\end{array}$ & $\begin{array}{l}\text { LP shaft } \\
\text { speed }\end{array}$ & Net thrust & $\begin{array}{l}\text { Fuel mass } \\
\text { flow rate }\end{array}$ \\
\hline $\begin{array}{l}\text { Training } \\
\text { data } \\
{[0 \sim 25} \\
\text { sec] }\end{array}$ & $793 \sim 978[K]$ & $797 \sim 1013[\mathrm{~K}]$ & $\begin{array}{l}6303 \sim \\
8694 \\
{[\mathrm{rpm}]}\end{array}$ & $\begin{array}{l}3.564 \sim \\
23.77[\mathrm{kN}]\end{array}$ & $\begin{array}{l}0.174 \sim \\
0.663[\mathrm{~kg} / \mathrm{s}]\end{array}$ \\
\hline $\begin{array}{l}\text { Validation } \\
\text { data } \\
{[25 \sim 35} \\
\text { sec] }\end{array}$ & $848 \sim 974[\mathrm{~K}]$ & $802 \sim 995[\mathrm{~K}]$ & $\begin{array}{l}6502 \sim \\
8509 \\
{[\mathrm{rpm}]}\end{array}$ & $\begin{array}{l}4.60 \sim \\
21.54[\mathrm{kN}]\end{array}$ & $\begin{array}{l}0.183 \tilde{r} \\
0.608[\mathrm{~kg} / \mathrm{s}]\end{array}$ \\
\hline
\end{tabular}

\section{Results}

Figure 7 shows the prediction results of the trained data-driven model. This model, trained using the measured temperature by the sensor, shows a difference between the predicted value and the test data at relatively low thrust conditions. Moreover, in the case of the fuel mass flow rate, the prediction accuracy of the original data-driven model was low. On the other hand, in the case of the data-driven model, which was learned using the fluid temperature calculated through the lumped system analysis method, the engine thrust and fuel flow prediction accuracy were higher than with the original data-driven model.

The prediction results for the fuel mass flow rate with the original and revised data-driven models are depicted in Figure 8. In the $0 \sim 25$ seconds measurement results used for learning, the trend is similar for the original data-driven model, but a local error can be observed. However, with 25 35 seconds measurement results used for validation, the accuracy of predicting the fuel mass flow rate of the original 
data-driven model is low, and the error increases over time. The revised data-driven model shows good agreement with the test data for both those used for training and validation.

Figure 9 presents a comparison between the original and revised data-driven models for the prediction of the engine net thrust. In the case of the original data-driven model, the prediction results and test data are well matched for the training data. However, the prediction accuracy for the validation data is low at the local minimum thrust region. The revised data-driven model accurately predicts engine thrust in all data ranges.

Figure 10 presents the estimated specific fuel consumption (SFC) of the engine using the original and revised data-driven models, which is defined as fuel consumption divided by engine net thrust. The SFC is the most important performance parameter in the engine. That is, whilst thermal efficiency is generally the key measurement for an industrial gas turbine engine, SFC is utilized for an aero gas turbine engine. That predicted by the original data-driven model shows a large difference in the trend and absolute value compared to the test data, with the error being larger in the validation data range than for the training data range. The revised data-driven model has higher SFC prediction accuracy compared to the original data-driven model.

The R-squared values for the estimated parameters using the data-driven model are summarized in Table 2. Regarding the fuel mass flow rate, the R-squared value has increased from 0.5513 to 0.9891 by using the revised data-driven model. The R-squared value for engine thrust with the revised data-driven model has increased from 0.9424 to 0.9951 compared with the original data-driven model. By applying the revised method, the R-squared value of the SFC seems to have the greatest improvement, with the value increasing from 0.1610 to 0.9348 . As a result, it is confirmed that the prediction accuracy is significantly lower when a data-driven model is trained using physically unsuitable data. On the other hand, it is concluded that the prediction accuracy can be improved when such a model is trained by processing data using a physical relationship.

Table 2

R-squared value for the estimated parameters in the validation data range
R-squared value for the original data- driven model
R-squared value for the revised data- driven model

$\begin{array}{lll}\begin{array}{l}\text { Fuel mass flow } \\ \text { rate }\end{array} & 0.5513 & 0.9891\end{array}$

Engine net

0.9424

0.9951

thrust

SFC

0.1610

0.9348

\section{Conclusion}


In this study, a new data-driven modeling method is introduced for an aero gas turbine engine system by take into account the time delay included in the measured temperature from a sensor. Analysis and verification have been performed based on the measurement data with high thrust fluctuation in an aircraft turbofan engine. A data-driven model has been trained by using the LP shaft speed and LPT total temperature as input parameters. The engine net thrust, and fuel mass flow rate have been predicted using the model. The conclusions drawn are summarized as follows.

- Lumped system analysis can effectively separate the measured and actual flow temperatures.

- The time delay error included in a temperature sensor adversely affects the accuracy of a data-driven model for predicting engine net thrust and the fuel mass flow rate.

- The prediction accuracy can be significantly improved when a data-driven model is trained based on the actual flow temperature separated from the measured values using a physical relationship.

- As a result, it was confirmed that the data-driven model with high prediction accuracy can be effectively generated by using the proposed method based on measurement data during dynamic operation.

\section{Abbreviation}

A area for heat transfer

ANN artificial neural network

b time constant in lumped system analysis

Cp heat capacity

$\mathrm{h}$ heat transfer coefficient

HPC high-pressure compressor

LPT low-pressure turbine

m mass

NARX nonlinear autoregressive neural network with exogenous inputs

SFC specific fuel consumption

t time

T temperature

\section{References}


1. Zhou, D., Yao, Q., Wu, H., Ma, S., \& Zhang, H. (2020). Fault diagnosis of gas turbine based on partly interpretable convolutional neural networks. Energy, 117467.

2. Orozco, D. J. R., Venturini, O. J., Palacio, J. C. E., \& del Olmo, O. A. (2017). A new methodology of thermodynamic diagnosis, using the thermoeconomic method together with an artificial neural network (ANN): A case study of an externally fired gas turbine (EFGT). Energy, 123, 20-35.

3. Tsoutsanis, E., \& Meskin, N. (2017). Derivative-driven window-based regression method for gas turbine performance prognostics. Energy, 128, 302-311.

4. Loboda, I., \& Yepifanov, S. (2010, October). A mixed data-driven and model based fault classification for gas turbine diagnosis. In Turbo Expo: Power for Land, Sea, and Air (Vol. 43987, pp. 257-265).

5. Aretakis, N., Roumeliotis, I., Doumouras, G., \& Mathioudakis, K. (2012). Compressor washing economic analysis and optimization for power generation. Applied energy, 95, 77-86.

6. Aretakis, N., Roumeliotis, I., \& Mathioudakis, K. (2011). Performance model "zooming" for in-depth component fault diagnosis. Journal of engineering for gas turbines and power, 133(3).

7. Lu, F., Zheng, W., Huang, J., \& Feng, M. (2016). Life cycle performance estimation and in-flight health monitoring for gas turbine engine. Journal of Dynamic Systems, Measurement, and Control, 138(9).

8. Sun, R., Shi, L., Yang, X., Wang, Y., \& Zhao, Q. (2020). A coupling diagnosis method of sensors faults in gas turbine control system. Energy, 117999.

9. Eggart, J., Thompson, C. E., Sasser, J., \& Merine, M. (2017). Heavy-Duty Gas Turbine Operating and Maintenance Considerations. GE Gas Turbine Reference Library, GER-3620N.

10. Sellers, J. F., \& Daniele, C. J. (1975). DYNGEN: A program for calculating steady-state and transient performance of turbojet and turbofan engines (Vol. 7901). National Aeronautics and Space Administration.

11. Lytle, J. K. (1999). The numerical propulsion system simulation: A multidisciplinary design system for aerospace vehicles.

12. Pang, S., Li, Q., Feng, H., \& Zhang, H. (2019). Joint steady state and transient performance adaptation for aero engine mathematical model. IEEE Access, 7, 36772-36787.

13. Ramadhan, E., Li, Y. G., \& Maherdianta, D. (2019, June). Application of Adaptive GPA to an Industrial Gas Turbine Using Field Data. In Turbo Expo: Power for Land, Sea, and Air (Vol. 58608, p. V003T23A008). American Society of Mechanical Engineers.

14. Li, S., Li, Z., \& Li, S. (2020). Improved Method for Gas-Turbine Off-Design Performance Adaptation Based on Field Data. Journal of Engineering for Gas Turbines and Power, 142(4).

15. Lo Gatto, E., Li, Y. G., \& Pilidis, P. (2006, January). Gas turbine off-design performance adaptation using a genetic algorithm. In Turbo Expo: Power for Land, Sea, and Air (Vol. 42371, pp. 551-560).

16. Li, Y. G., Ghafir, M. F., Wang, L., Singh, R., Huang, K., \& Feng, X. (2011). Nonlinear multiple points gas turbine off-design performance adaptation using a genetic algorithm. Journal of Engineering for Gas Turbines and Power, 133(7). 
17. Tsoutsanis, E., Meskin, N., Benammar, M., \& Khorasani, K. (2014). A component map tuning method for performance prediction and diagnostics of gas turbine compressors. Applied Energy, 135, 572585.

18. Kim, S., Kim, K., \& Son, C. (2018). Adaptation method for overall and local performances of gas turbine engine model. International Journal of Aeronautical and Space Sciences, 19(1), 250-261.

19. Basso, M., Giarre, L., Groppi, S., \& Zappa, G. (2005). NARX models of an industrial power plant gas turbine. IEEE Transactions on control systems technology, 13(4), 599-604.

20. Nikpey, H., Assadi, M., \& Breuhaus, P. (2012, July). Development of an artificial neural network model for combined heat and power micro gas turbines. In 2012 International Symposium on Innovations in Intelligent Systems and Applications (pp. 1-5). IEEE.

21. Rahnama, M., Ghorbani, H., \& Montazeri, A. (2012, December). Nonlinear identification of a gas turbine system in transient operation mode using neural network. In The 4th Conference on Thermal Power Plants (pp. 1-6). IEEE.

22. Lu, Y., \& Gao, Z. (2014, June). Data-driven model reduction and fault diagnosis for an aero gas turbine engine. In 2014 9th IEEE Conference on Industrial Electronics and Applications (pp. 19361941). IEEE.

23. Asgari, H., Chen, X., Morini, M., Pinelli, M., Sainudiin, R., Spina, P. R., \& Venturini, M. (2016). NARX models for simulation of the start-up operation of a single-shaft gas turbine. Applied Thermal Engineering, 93, 368-376.

24. Yu, B., \& Shu, W. (2017, March). Research on turbofan engine model above idle state based on narx modeling approach. In Materials Science and Engineering Conference Series. Materials Science and Engineering Conference Series. England: IOP Conference Series (Vol. 12002).

25. Bahlawan, H., Morini, M., Pinelli, M., Ruggero Spina, P., \& Venturini, M. (2018). Development of Reliable NARX Models of Gas Turbine Cold, Warm, and Hot Start-Up. Journal of Engineering for Gas Turbines and Power, 140(7).

26. Salehi, A., \& Montazeri-Gh, M. (2019). Black box modeling of a turboshaft gas turbine engine fuel control unit based on neural NARX. Proceedings of the Institution of Mechanical Engineers, Part M: Journal of Engineering for the Maritime Environment, 233(3), 949-956.

27. De Giorgi, M. G., Ficarella, A., \& Quarta, M. (2019). Dynamic performance simulation and control of an aeroengine by using NARX models. In MATEC Web of Conferences (Vol. 304, p. 03005). EDP Sciences.

28. Liu, Z., \& Karimi, I. A. (2020). Gas turbine performance prediction via machine learning. Energy, 192, 116627.

29. Kim, S., Kim, K., \& Son, C. (2020). Transient system simulation for an aircraft engine using a datadriven model. Energy, 196, 117046.

30. Paniagua, G., De' nos, R., \& Oropesa, M. (2002). Thermocouple probes for accurate temperature measurements in short duration facilities (Vol. 3607, pp. 209-217). 
31. Atkins, N. R., Miller, R. J., \& Ainsworth, R. W. (2004, January). The development of aerodynamic performance measurements in a transient test facility. In Turbo Expo: Power for Land, Sea, and Air (Vol. 41707, pp. 1325-1338).

32. Gaylord, A. M., Compton, W. A., \& Furgurson, R. G. (1969, March). High temperature sensors for gas turbines. In ASME 1969 Gas Turbine Conference and Products Show (pp. V001T01A030V001T01A030). American Society of Mechanical Engineers.

33. Kim, S., Kim, K., \& Son, C. (2020). A new transient performance adaptation method for an aero gas turbine engine. Energy, 193, 116752.

34. Ray, R. (1994, June). Evaluating the dynamic response of in-flight thrust calculation techniques during throttle transients. In Biennial flight test conference (p. 2115).

\section{Figures}

Real Gas Turbine Engine

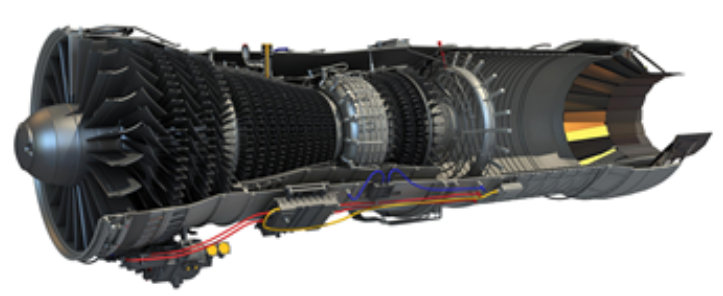

Measurement Data

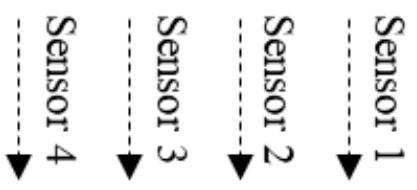

Measurement data treatment

Measurement data treatment based on physics-based model (Thermodynamic relations)
Measurement Data

\section{Sensor 1}

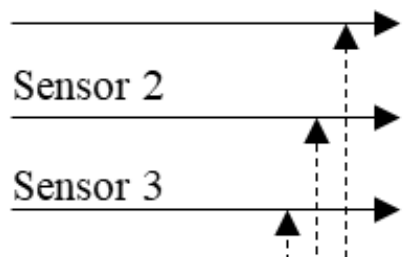

Sensor 4

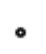

$\bullet$

$\bullet$
Machine Learning

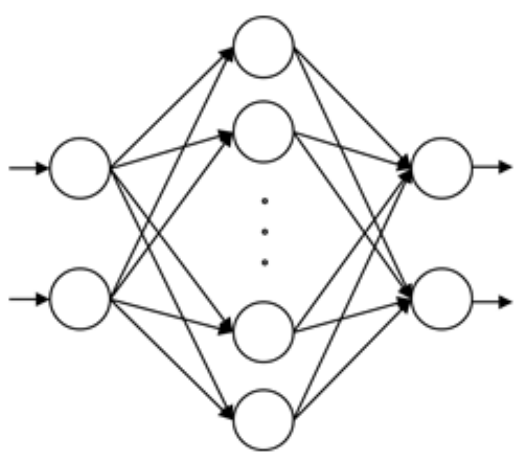

Final Data-Driven Model

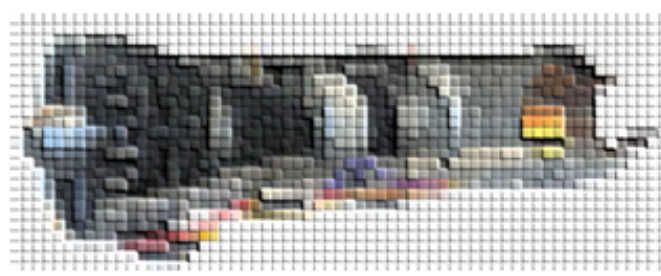

(Digital Engine Model)

Measurement data flow (Conventional approach)

Measurement data flow (Proposed approach)

\section{Figure 1}

Schematic flow chart for the data-driven model generation with the conventional and proposed approaches 


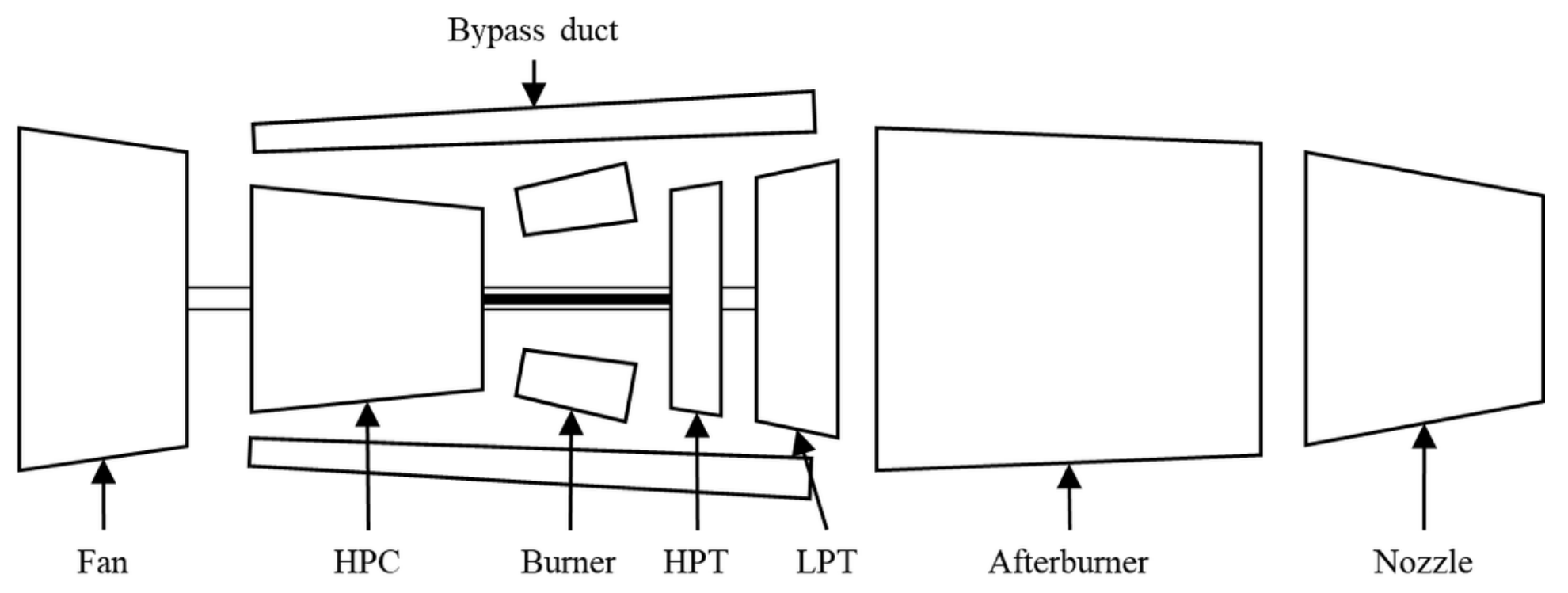

Figure 2

Schematics of an F100 turbofan engine 

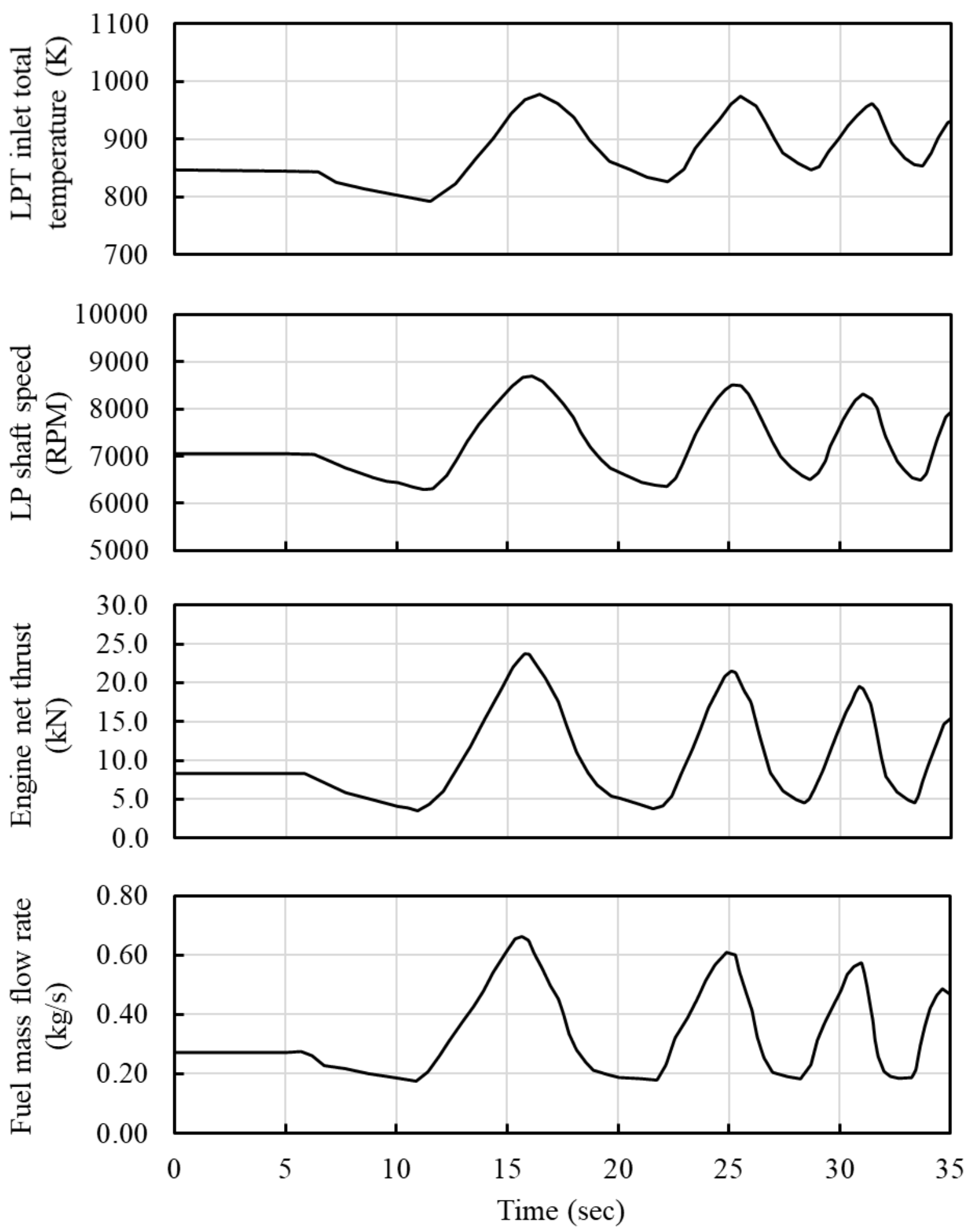

Figure 3

Measurement data for a throttle frequency sweep maneuver [34] 


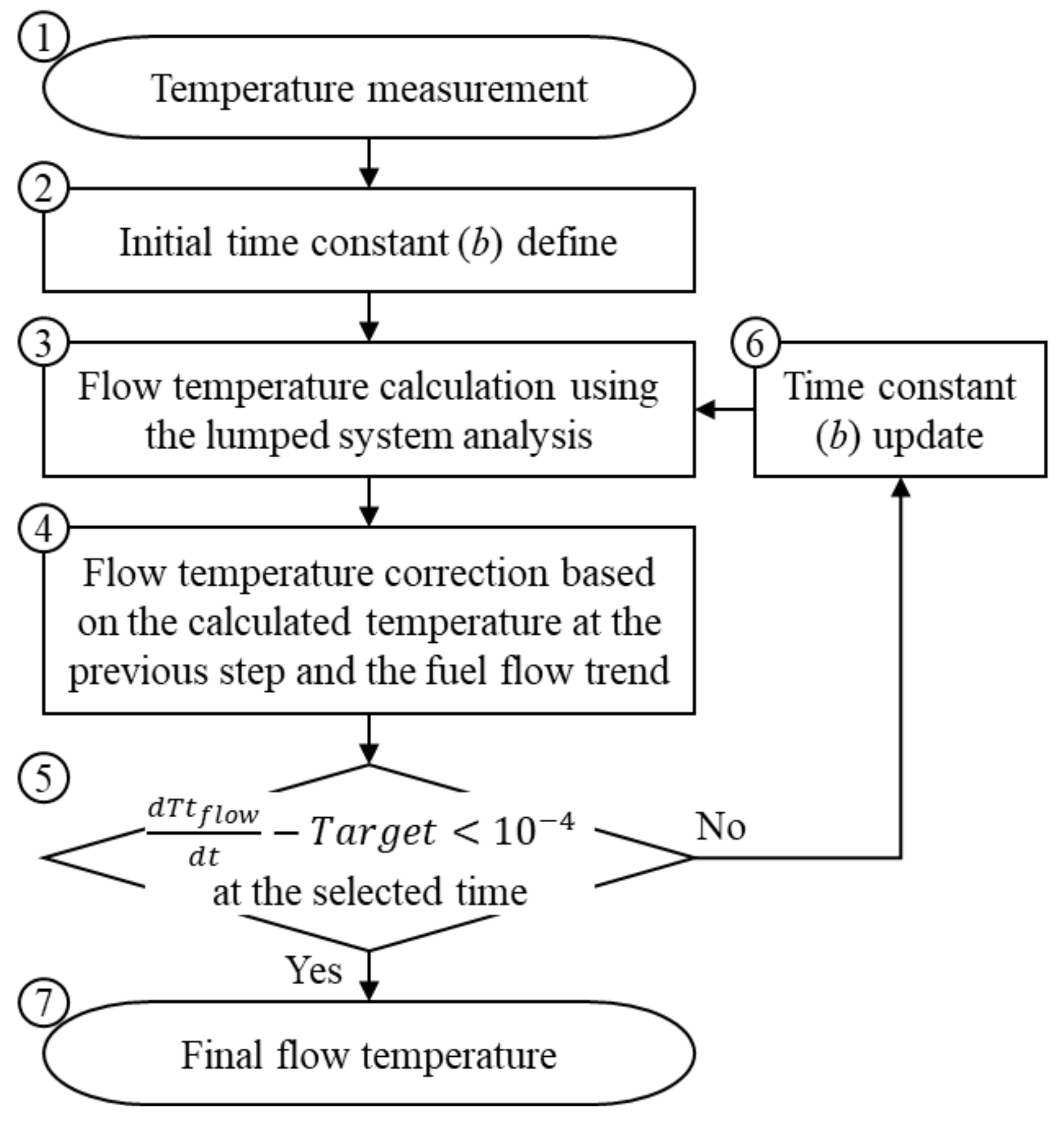

Figure 4

Flow chart for the measured temperature treatment 


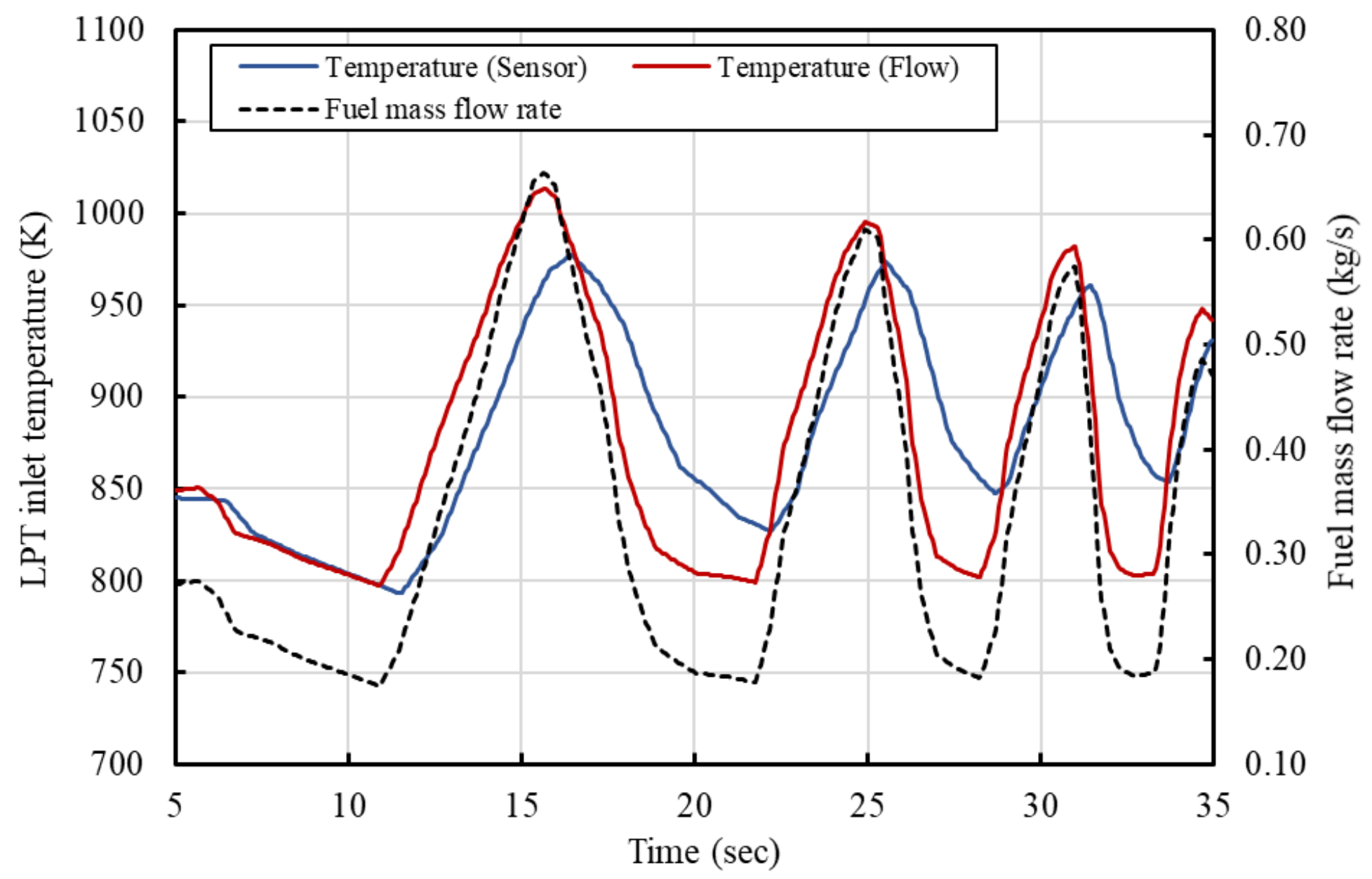

Figure 5

Comparison between sensor and estimated flow temperatures 


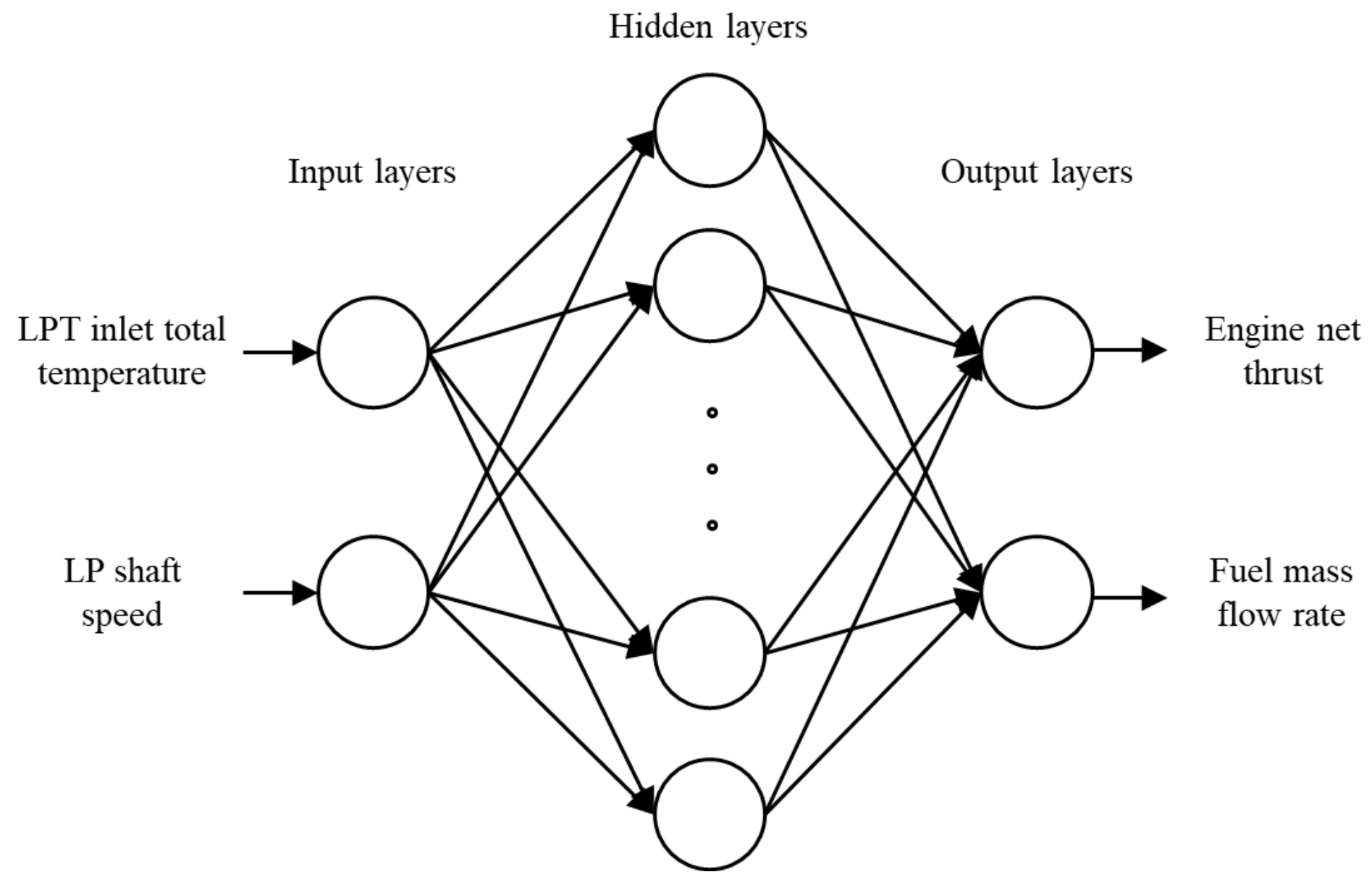

Figure 6

Schematics of a feed forward neural network for data-driven modeling 


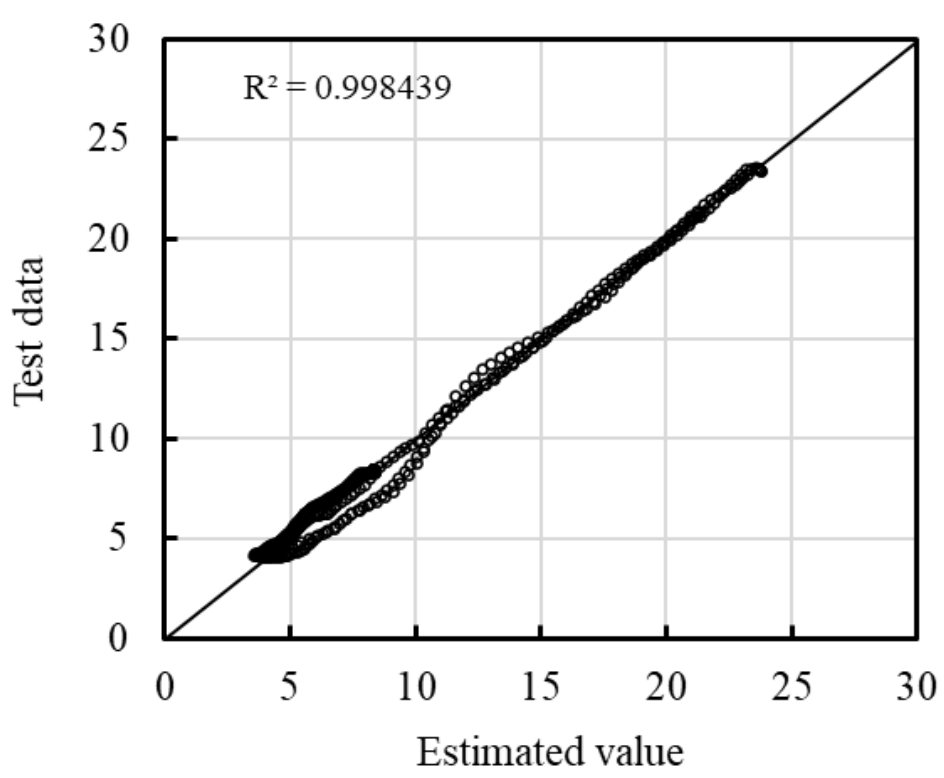

(a) Net thrust estimation using original data-driven model

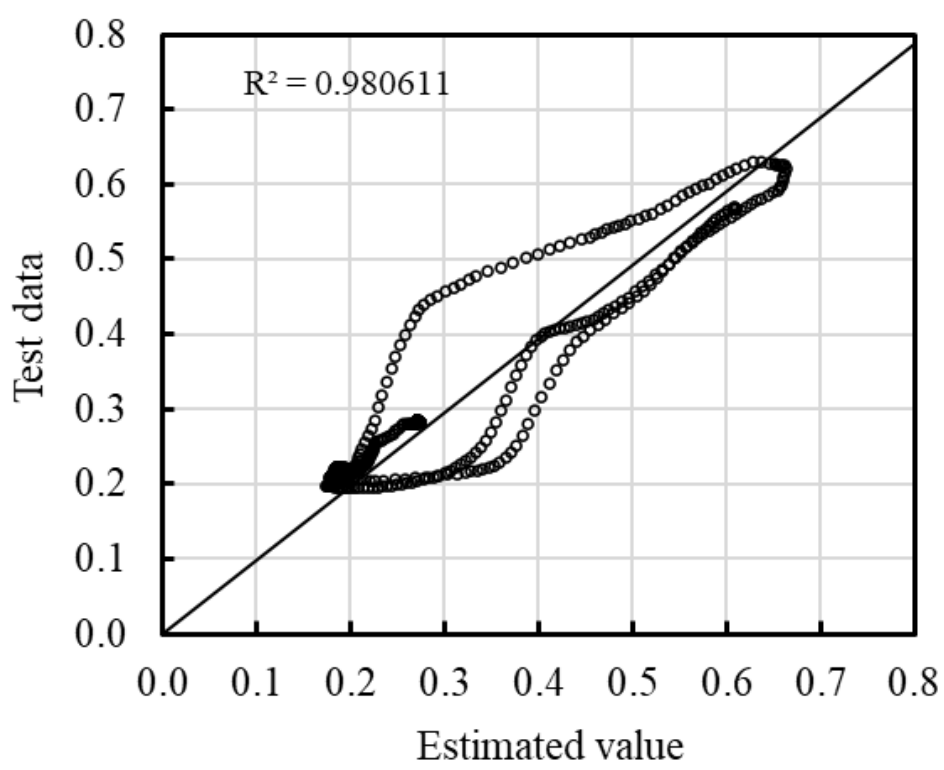

(c) Fuel mass flow rate estimation using original data-driven model

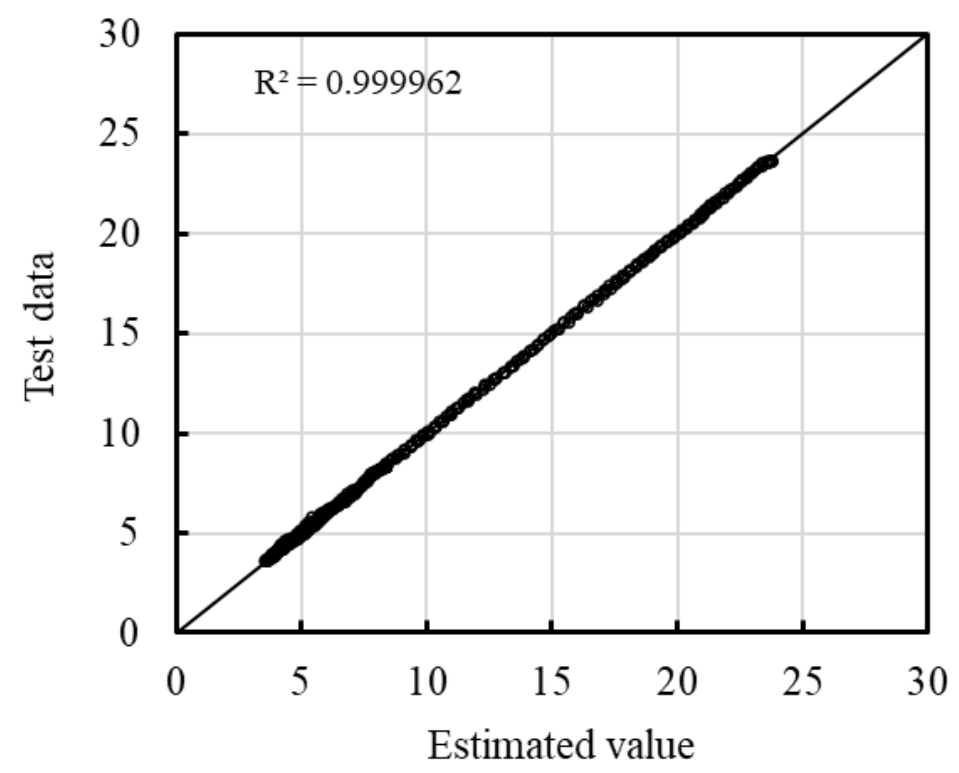

(b) Net thrust estimation using revised data-driven model

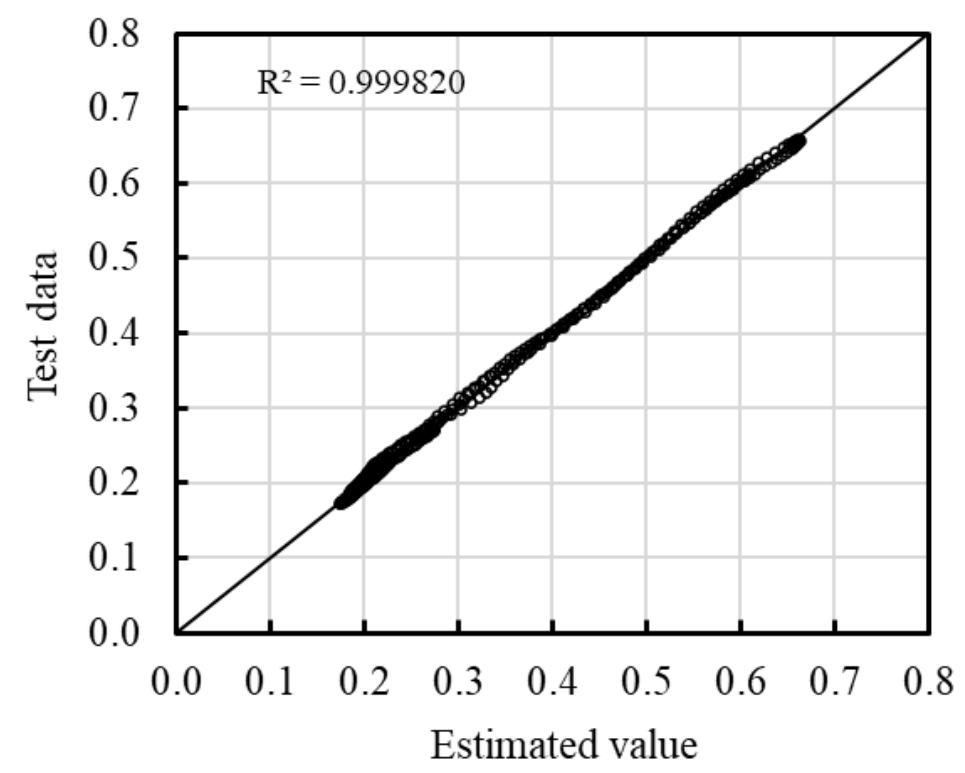

(d) Fuel mass flow rate estimation using revised data-driven model

Figure 7

R-squared comparison for the original and revised data-driven models 


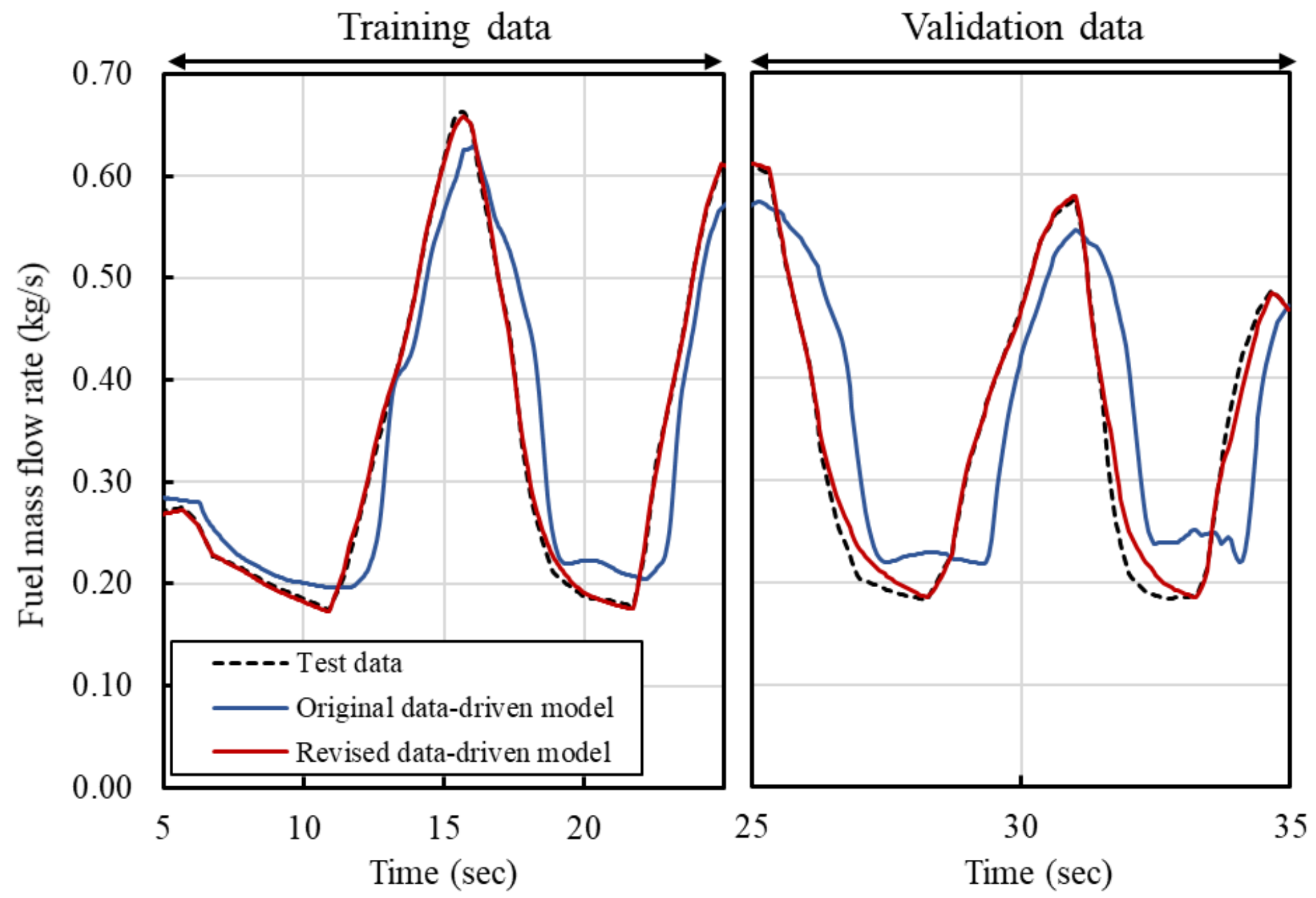

Figure 8

Fuel mass flow rate estimation using the original and revised data-driven models 


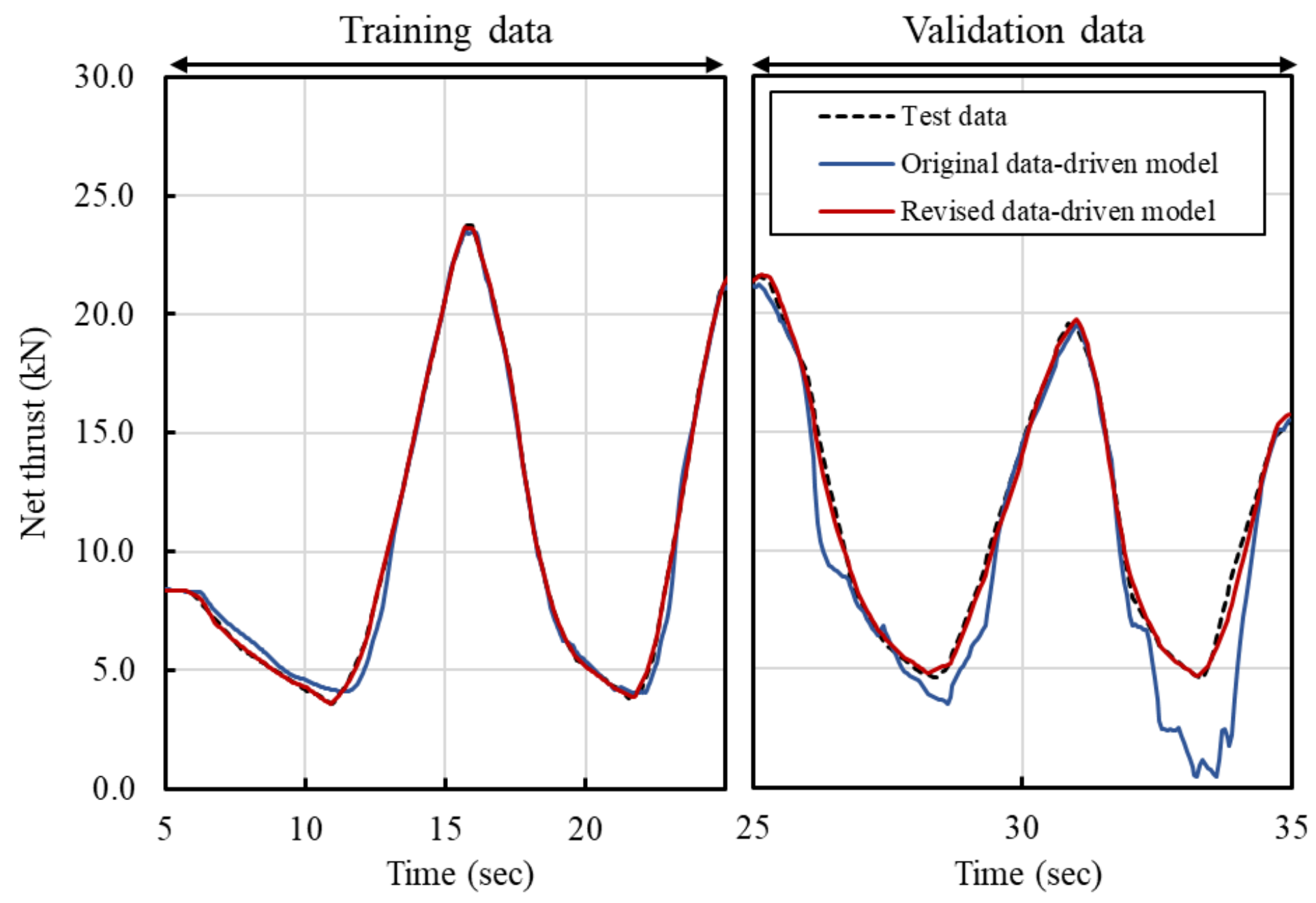

Figure 9

Net thrust estimation using the original and revised data-driven models 


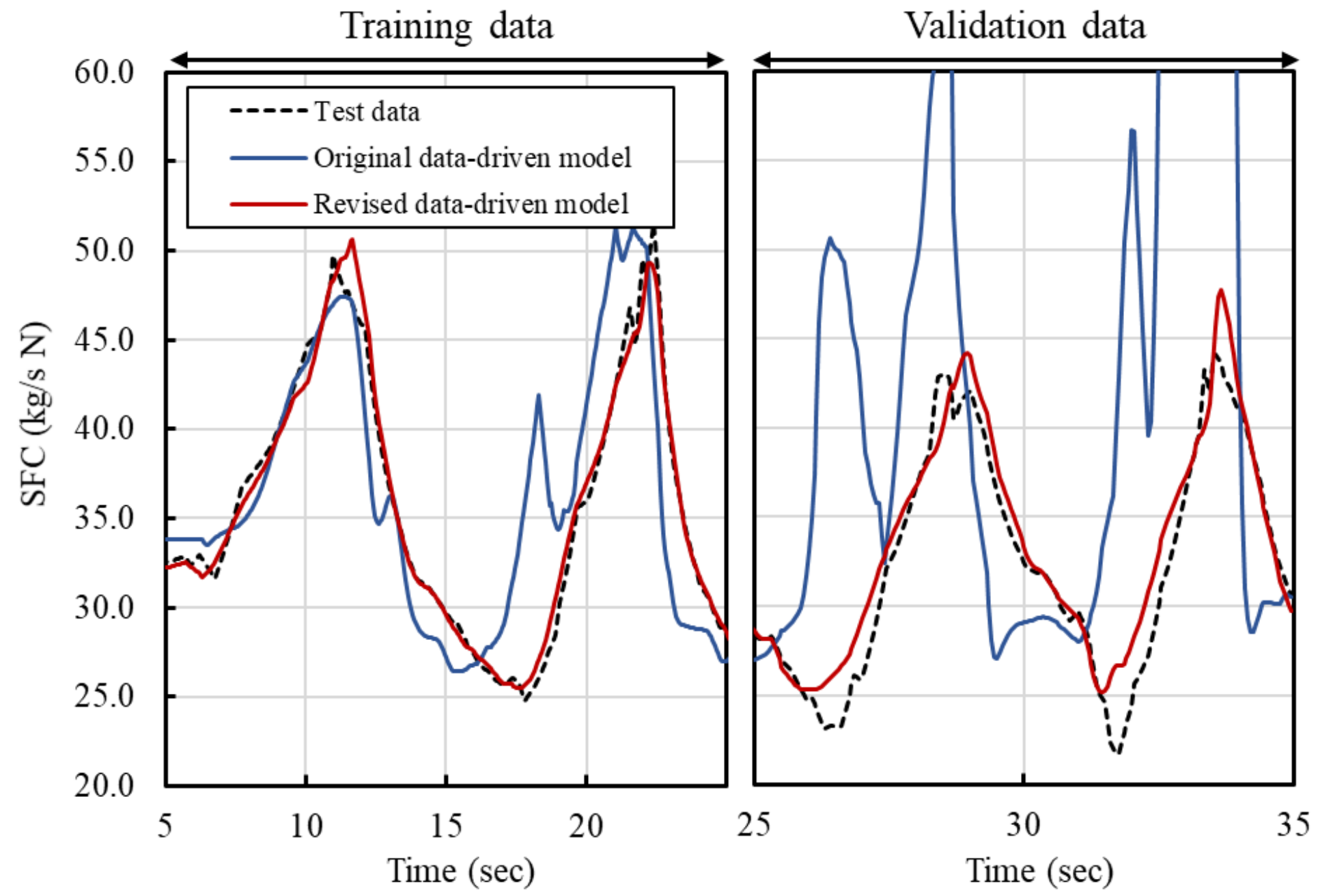

Figure 10

SFC estimation using the original and revised data-driven models 